\title{
NOTE \\ Internal Medicine \\ Prognostic significance of midline shift of the olfactory or frontal lobes of the brain in canine nasal carcinomas treated by palliative radiotherapy: a pilot study
}

\author{
Yusuke WADA ${ }^{1)}$, Shunsuke NOGUCHI ${ }^{2) *}$, Hiromitsu SASAKI ${ }^{1}$, Ai TAKETOMI ${ }^{1}$, \\ Mizuho HAMAKAWA ${ }^{1)}$, Shunsuke SHIMAMURA ${ }^{1)}$ and Terumasa SHIMADA ${ }^{1)}$ \\ ${ }^{1)}$ Veterinary Medical Center, Osaka Prefecture University, 1-58 Rinku Ourai Kita, Izumisano-shi, Osaka 598-8531, \\ Japan \\ 2)Laboratory of Veterinary Radiology, Graduate School of Life and Environmental Sciences, Osaka Prefecture \\ University, 1-58 Rinku Ourai Kita, Izumisano-shi, Osaka 598-8513, Japan
}

J. Vet. Med. Sci.
80(11): 1724-1727, 2018
doi: 10.1292/jvms.18-0347

Received: 23 June 2018

Accepted: 15 September 2018

Published online in J-STAGE:

11 October 2018
ABSTRACT. Canine nasal carcinomas are often treated with radiotherapy. Presence of lysis of the cribriform plate by tumor invasion (stage 4 by modified Adams's staging system) is a well-known prognostic factor. In this study, dogs with stage 4 disease were divided into two subgroups based on the presence or absence of midline shift of the olfactory or frontal lobes of the brain (Stage $4 \mathrm{a}$ : without presence of midline shift. Stage $4 \mathrm{~b}$ : with midline shift). The median survival time of dogs with midline shift was significantly shorter than that of dogs without midline shift (64 vs. 208 days). Our results indicate that the finding of a midline shift might have a prognostic significance in dogs with nasal carcinoma treated with radiotherapy.

KEY WORDS: dog, nasal carcinoma, prognosis, radiotherapy

Nasal tumors account for $1-2 \%$ of all reported canine neoplasms $[9,10]$. Carcinomas comprise two-thirds of canine intranasal tumors and are characterized by progressive local invasion and low metastatic rate [15]. Without treatment, the median survival time (MST) of dogs with nasal tumors has been reported to be 3.1 months [13]. The most common therapy for these carcinomas is high-voltage radiotherapy using megavoltage x-rays; surgery alone has proven to be of little benefit in prolonging survival time [13]. The MST of dogs treated with radiotherapy is 4.9-19.7 months [1, 3-6, 11].

Studies have reported many prognostic factors for canine nasal tumors including the presence of epistaxis, histological tumor type, age, and clinical stage $[1,8,13]$. For clinical staging, several methods have been suggested. Application of the World Health Organization staging method to canine nasal tumors is known to have no prognostic relevance [7, 14]. More recently, Adams et al. have advocated a new staging method that showed an association between clinical stage and prognosis [1]. This classification showed that the MST of the dogs with stage 4 disease (tumor with cribriform plate destruction) was the shortest compared with that for other stages (e.g. stage 1-23.4 months vs. stage 4-6.7 months) after radiotherapy. Therefore, a modified Adams's classification has often been used in previous studies. On the other hand, Agthe et al. reported that caudal nasal recess involvement, meningeal hyperintensity, and intracranial tumor extension tended to be associated with shorter survival, as assessed by magnetic resonance imaging (MRI) [2]. In this way, cribriform plate destruction alone may not always predict survival time for dogs with advanced nasal tumors. Based on these findings, we investigated factors influencing survival in dogs with stage 4 disease. We focused on the association between a midline shift of the olfactory or frontal lobes of the brain, as detected by computed tomography (CT), and survival time after radiotherapy.

This was a retrospective observational study. The medical records of dogs with stage 4 nasal carcinoma treated at the Veterinary Medical Center of Osaka Prefecture University between 2014 and 2017 were retrospectively reviewed for cases that had received palliative radiotherapy. Dogs that had concurrently received surgery or re-radiotherapy were excluded from this study.

Complete blood cell counts, serum biochemical profile, and histopathological diagnosis before radiotherapy had been performed on all subjects. Prior to radiotherapy, CT of the head was performed on the dogs when properly positioned and immobilized with a bite block and a vacuum bag. As shown in Fig. 1, all patients could be divided into 2 groups according to the presence or absence of a midline shift of the olfactory or frontal lobes of the brain as evidenced on CT (stage 4a, without presence of midline shift; stage $4 \mathrm{~b}$, with midline shift). We defined the midline shift as a $>2 \mathrm{~mm}$ departure from a line connecting the dorsal and ventral

*Correspondence to: Noguchi, S.: snoguchi@vet.osakafu-u.ac.jp

O2018 The Japanese Society of Veterinary Science

This is an open-access article distributed under the terms of the Creative Commons Attribution Non-Commercial No Derivatives (by-nc-nd) License. (CC-BY-NC-ND 4.0: https://creativecommons.org/licenses/by-nc-nd/4.o/) 
(A)

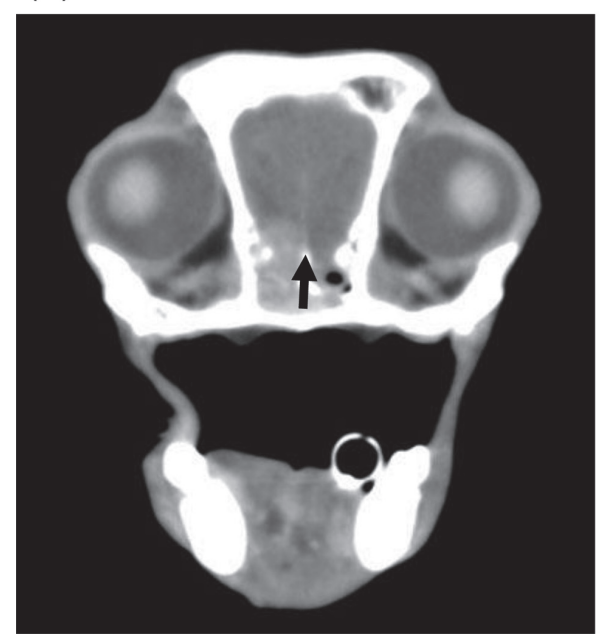

(B)

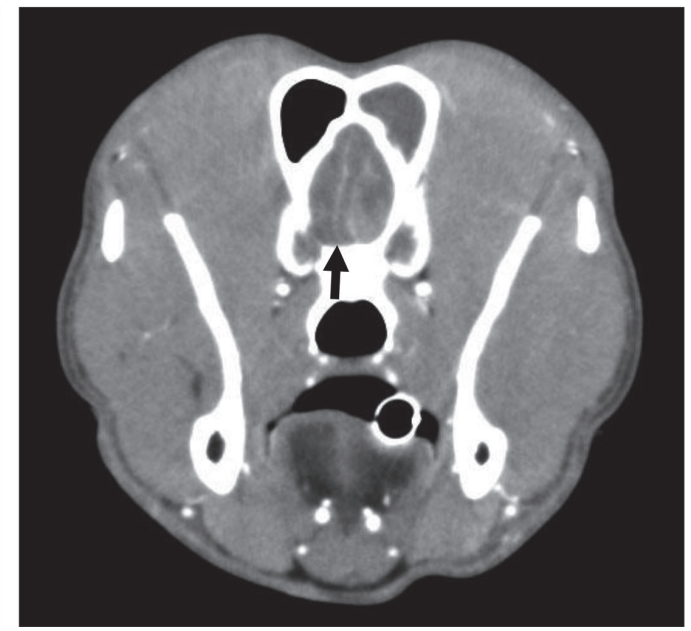

Fig. 1. Representative images of stage $4 a(A)$ and stage $4 b(B)$ in the transverse plane of contrast-enhanced CT. Arrows indicates midline of olfactory bulb (B) and frontal lobe (A) of the brain.

falx cerebri . Further, the regional lymph node status was evaluated by performing a CT scan. Information about the dogs was obtained from medical records or telephone interviews with the owner or referring veterinarian including their breed, age, clinical symptoms, survival time, and cause of death.

All dogs had received 3D-conformal radiation therapy: 4 doses of 8-9 Gy megavoltage radiotherapy given at 7-day intervals by a 4 MV X-ray linear accelerator (PRIMUS; Toshiba Medical Systems Corp., Tochigi, Japan). Individualized treatment plans were generated with 3D treatment planning software (XiO, Elekta Japan, Tokyo, Japan). The gross tumor volume (GTV) was contoured using $2 \mathrm{~mm}$ slice thickness CT image sets and included contrast-enhancing mass containing discharge and the brain area where the tumor was suspected to have invaded. Planning target volume (PTV) included the region $0.3-0.5 \mathrm{~cm}$ outside the GTV. The prescription point of radiation dose was set at the isocenter, covering over $80 \%$ of the PTV. Wedges were used, if necessary, for a homogenous dose distribution.

Survival analysis was performed using commercial statistical software GraphPad Prism 7 (GraphPad software, La Jolla, CA, U.S.A.). Survival was defined as the interval between the date of start of radiotherapy and time of death. Dogs that remained alive at the end of the study, died from some unrelated cause or were euthanized were censored in the survival analysis. The Kaplan-Meier method was used to prepare overall survival (OS) curves, while the log-rank test was used to compare time-to-event distributions. A $P$-value of $<0.05$ was considered significant for all analyses.

Sixteen dogs were included in this study. There were 8 males (of which 3 had been castrated) and 8 females (all of which had been spayed). Their ages ranged from 7 to 17 years (median, 11.5 years). There were 2 mixed-breed dogs and the following 14 pure-breed ones: Shiba $(n=4)$, Miniature Dachshund $(n=3)$, Chihuahua $(n=2)$, Welsh Corgi $(n=1)$, Shetland Sheepdog ( $n=1)$, Maltese $(n=1)$, Pug $(n=1)$, and Sealyham Terrier $(n=1)$. Tumor types included adenocarcinoma $(n=13)$, transitional nasal carcinoma $(n=1)$, undifferentiated carcinoma $(n=1)$, and carcinoma $(n=1)$. Eight dogs had tumor stage $4 a$ and eight had stage $4 b$. Two dogs received chemotherapy with toceranib (Palladia ${ }^{\circledR}$, Zoetis, Tokyo, Japan) after radiotherapy. The characteristics of all patients are summarized in Table 1 .

Clinical symptoms observed before radiotherapy included epistaxis $(n=14)$, dyspnea $(n=7)$, facial deformity $(n=6)$, neurologic abnormality (seizure, $n=4$; head tilt, $n=1$ ), and lymphadenopathy $(n=7)$. Cytological or histological examination of lymph nodes was not performed.

Of the 16 dogs, 2 were alive at the end of the study. Thirteen dogs died due to tumor related or other causes and 1 dog was euthanized due to tumor progression. The MST for all dogs was 120.5 days (range, 38-476 days; Fig. 2), which was shorter than that reported in a previous study by Maruo et al., in which the MST of the dogs with cribriform plate destruction was 163 days after treatment with the same radiotherapy protocol (median total dose was $32 \mathrm{~Gy}$ ) [11]. We hypothesized that the reason for this short time survival was due to a difference of severity in stage 4. Another report indicated that tumor extension into the cranium was associated with shorter survival in dogs with nasal tumors treated with radiotherapy [2]. Thus, we focused on the midline shift of the olfactory bulb or frontal lobes of the brain. The MST of dogs with stage 4a (208 days) was significantly longer than that of those with stage $4 b$ ( 64 days; Fig. 3 and Table 2). The results allowed us to consider that the proportion of stage $4 b$ ( 8 of 16 dogs) was responsible for the overall shorter MST in this study.

The known prognostic factors for nasal carcinoma include tumor type, stage, epistaxis, age, regional lymph node or pulmonary metastasis, and facial deformity $[1,7,8,12,13]$. However, there was no significant difference in the MST based on pre-therapy clinical symptoms (epistaxis, dyspnea, facial deformity, neurologic abnormality, and lymphadenopathy; Table 2). We did not evaluate for metastasis to regional lymph nodes in all cases, although there were none with pulmonary metastasis, which had been 
Table 1. Patient information

\begin{tabular}{|c|c|c|c|c|c|c|c|c|c|}
\hline No. & Sex & Age & Breed & Diagnosis & $\begin{array}{c}\text { Clinical } \\
\text { stage }\end{array}$ & $\begin{array}{l}\text { Survival time } \\
\text { (day) }\end{array}$ & $\begin{array}{l}\text { Adjuvant } \\
\text { therapy }\end{array}$ & Outcome & Cause of death \\
\hline 1 & $\mathrm{SF}$ & 17 & Miniture Dachshund & Adenocarcinoma & $4 \mathrm{a}$ & 38 & None & Death & Tumor related \\
\hline 2 & SF & 11 & Welsh Corgi & Adenocarcinoma & $4 a$ & 171 & None & Death & Euthanasia \\
\hline 3 & SF & 12 & Shiba & Adenocarcinoma & $4 a$ & 208 & None & Death & Tumor related \\
\hline 4 & $\mathrm{CM}$ & 13 & Shiba & Transitional carcinoma & $4 \mathrm{a}$ & 111 & None & Death & Unknown \\
\hline 5 & M & 12 & Chihuahua & Undifferentiated carcinoma & $4 \mathrm{a}$ & 476 & None & Alive & \\
\hline 6 & $\mathrm{CM}$ & 12 & Mixed & Adenocarcinoma & $4 \mathrm{a}$ & 288 & Toceranib & Death & Tumor related \\
\hline 7 & SF & 13 & Shetland Sheepdog & Adenocarcinoma & $4 a$ & 202 & Toceranib & Death & Arrythmia \\
\hline 8 & M & 10 & Maltese & Adenocarcinoma & $4 a$ & 204 & None & Alive & \\
\hline 9 & $\mathrm{SF}$ & 11 & Mongrel & Adenocarcinoma & $4 \mathrm{~b}$ & 49 & None & Death & Tumor related \\
\hline 10 & $\mathrm{SF}$ & 10 & Miniture Dachshund & Adenocarcinoma & $4 \mathrm{~b}$ & 55 & None & Death & Tumor related \\
\hline 11 & M & 7 & Pug & Adenocarcinoma & $4 \mathrm{~b}$ & 129 & None & Death & Tumor related \\
\hline 12 & $\mathrm{M}$ & 12 & Shiba & Adenocarcinoma & $4 \mathrm{~b}$ & 154 & None & Death & Tumor related \\
\hline 13 & $\mathrm{M}$ & 14 & Shiba & Adenocarcinoma & $4 \mathrm{~b}$ & 56 & None & Death & Tumor related \\
\hline 14 & SF & 10 & Miniture Dachshund & Adenocarcinoma & $4 \mathrm{~b}$ & 112 & None & Death & Tumor related \\
\hline 15 & $\mathrm{CM}$ & 11 & Chihuahua & Adenocarcinoma & $4 \mathrm{~b}$ & 58 & None & Death & Tumor related \\
\hline 16 & SF & 11 & Sealyham Terrier & Carcinoma & $4 \mathrm{~b}$ & 70 & None & Death & Tumor related \\
\hline
\end{tabular}

$\mathrm{SF}$, spayed female; $\mathrm{CM}$, castrated male; $\mathrm{M}$, male.

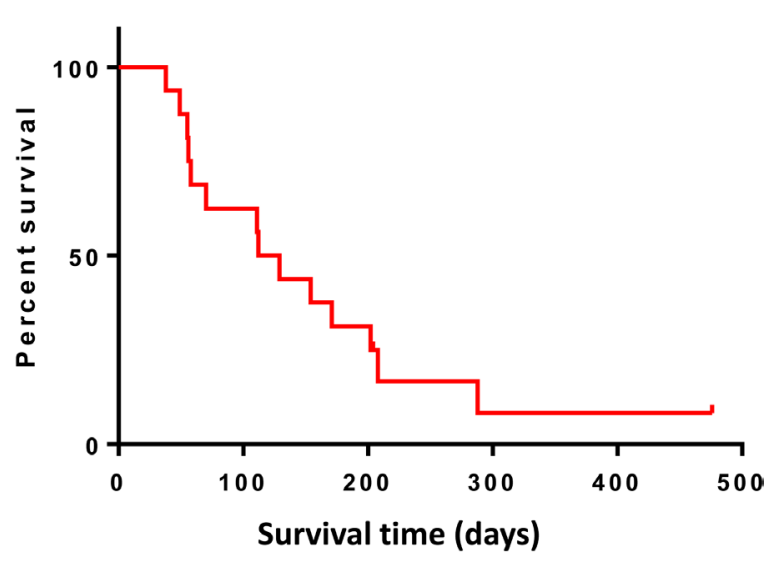

Fig. 2. Kaplan-Meier survival curve of survival time for 16 dogs with nasal tumor in stage 4. In our study, the MST was 120.5 days.

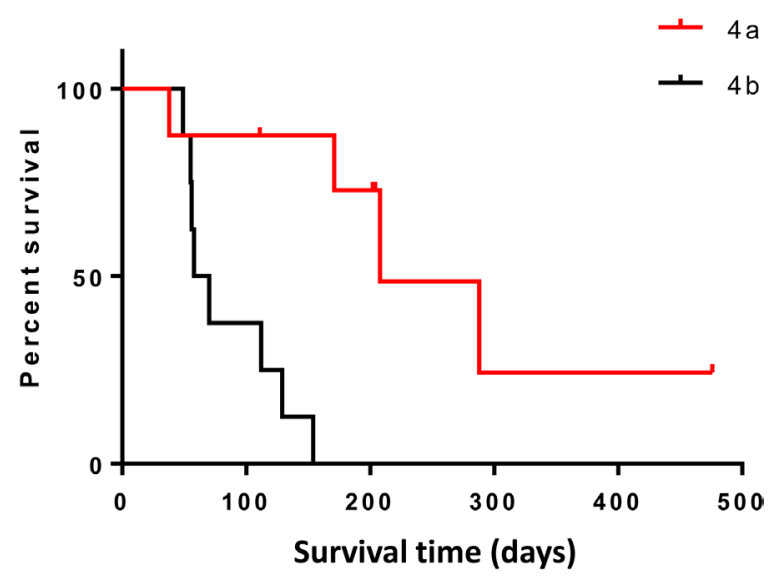

Fig. 3. Kaplan-Meier survival curves of the dogs with stage 4a and stage $4 \mathrm{~b}$ tumors. The red line is stage $4 \mathrm{a}$ with an MST of 208 days $(n=8)$, and the black line, stage $4 \mathrm{~b}$ with an MST of 64 days $(n=8)$.

Table 2. Median survival times for all dogs included in the study

\begin{tabular}{|c|c|c|c|c|}
\hline Characteristic & & $\begin{array}{c}\text { Number with } \\
\text { characteristic (\%) }\end{array}$ & $\begin{array}{l}\text { Median survival } \\
\text { time (day) }\end{array}$ & $P$ value \\
\hline \multirow[t]{2}{*}{ Midline shift } & Yes & $8(50)$ & 64 & \multirow{2}{*}{0.0015} \\
\hline & No & $8(50)$ & 208 & \\
\hline \multirow[t]{2}{*}{ Epistaxis } & Yes & $14(88)$ & 141.5 & \multirow{2}{*}{0.1517} \\
\hline & No & $2(12)$ & 80.5 & \\
\hline \multirow[t]{2}{*}{ Dyspnea } & Yes & $7(44)$ & 204 & \multirow{2}{*}{0.3794} \\
\hline & No & $9(56)$ & 70 & \\
\hline \multirow[t]{2}{*}{ Facial deformity } & Yes & $6(38)$ & 181 & \multirow{2}{*}{0.2163} \\
\hline & No & $10(62)$ & 111.5 & \\
\hline \multirow[t]{2}{*}{ Neurologic abnormality } & Yes & $5(31)$ & 112 & \multirow{2}{*}{0.4587} \\
\hline & No & $11(69)$ & 129 & \\
\hline \multirow[t]{2}{*}{ Lymphadenopathy } & Yes & $7(44)$ & 154 & \multirow{2}{*}{0.4533} \\
\hline & No & $9(56)$ & 111 & \\
\hline
\end{tabular}


assessed by CT.

The major limitation of this study was the small sample set, which possibly reflected a statistical error. Despite these limitations, this study suggests that dogs with stage $4 \mathrm{~b}$ disease have a short survival period (MST, 64 days). These results indicate that radiation therapy for dogs with stage $4 \mathrm{~b}$ tumors might be able to improve their clinical symptoms, but not prolong survival time. Further studies with a larger population are needed to validate the prognostic significance of a midline shift in cases with stage 4 nasal tumors.

ACKNOWLEDGMENTS. The authors would like to acknowledge all veterinarians who participated in this study.

\section{REFERENCES}

1. Adams, W. M., Kleiter, M. M., Thrall, D. E., Klauer, J. M., Forrest, L. J., La Due, T. A. and Havighurst, T. C. 2009. Prognostic significance of tumor histology and computed tomographic staging for radiation treatment response of canine nasal tumors. Vet. Radiol. Ultrasound 50: 330-335. [Medline] [CrossRef]

2. Agthe, P., Caine, A. R., Gear, R. N., Dobson, J. M., Richardson, K. J. and Herrtage, M. E. 2009. Prognostic significance of specific magnetic resonance imaging features in canine nasal tumours treated by radiotherapy. J. Small Anim. Pract. 50: 641-648. [Medline] [CrossRef]

3. Cancedda, S., Sabattini, S., Bettini, G., Leone, V. F., Laganga, P., Rossi, F., Terragni, R., Gnudi, G. and Vignoli, M. 2015. Combination of radiation therapy and firocoxib for the treatment of canine nasal carcinoma. Vet. Radiol. Ultrasound 56: 335-343. [Medline] [CrossRef]

4. Fujiwara, A., Kobayashi, T., Kazato, Y., Yayoshi, N. and Fujita, M. 2013. Efficacy of hypofractionated radiotherapy for nasal tumours in 38 dogs (2005-2008). J. Small Anim. Pract. 54: 80-86. [Medline] [CrossRef]

5. Gieger, T., Rassnick, K., Siegel, S., Proulx, D., Bergman, P., Anderson, C., LaDue, T., Smith, A., Northrup, N. and Roberts, R. 2008. Palliation of clinical signs in 48 dogs with nasal carcinomas treated with coarse-fraction radiation therapy. J. Am. Anim. Hosp. Assoc. 44: 116-123. [Medline] [CrossRef]

6. Gieger, T. L. and Nolan, M. W. 2018. Linac-based stereotactic radiation therapy for canine non-lymphomatous nasal tumours: 29 cases (2013-2016). Vet. Comp. Oncol. 16: E68-E75. [Medline] [CrossRef]

7. Henry, C. J., Brewer, W. G. Jr., Tyler, J. W., Brawner, W. R., Henderson, R. A., Hankes, G. H. and Royer, N. 1998. Survival in dogs with nasal adenocarcinoma: 64 cases (1981-1995). J. Vet. Intern. Med. 12: 436-439. [Medline] [CrossRef]

8. LaDue, T. A., Dodge, R., Page, R. L., Price, G. S., Hauck, M. L. and Thrall, D. E. 1999. Factors influencing survival after radiotherapy of nasal tumors in 130 dogs. Vet. Radiol. Ultrasound 40: 312-317. [Medline] [CrossRef]

9. MacEwen, E. G., Withrow, S. J. and Patnaik, A. K. 1977. Nasal tumors in the dog: retrospective evaluation of diagnosis, prognosis, and treatment. J. Am. Vet. Med. Assoc. 170: 45-48. [Medline]

10. Madewell, B. R., Priester, W. A., Gillette, E. L. and Snyder, S. P. 1976. Neoplasms of the nasal passages and paranasal sinuses in domesticated animals as reported by 13 veterinary colleges. Am. J. Vet. Res. 37: 851-856. [Medline]

11. Maruo, T., Shida, T., Fukuyama, Y., Hosaka, S., Noda, M., Ito, T., Sugiyama, H., Ishikawa, T. and Madarame, H. 2011. Retrospective study of canine nasal tumor treated with hypofractionated radiotherapy. J. Vet. Med. Sci. 73: 193-197. [Medline] [CrossRef]

12. Northrup, N. C., Etue, S. M., Ruslander, D. M., Rassnick, K. M., Hutto, D. L., Bengtson, A., Rand, W. and Moore, A. S. 2001. Retrospective study of orthovoltage radiation therapy for nasal tumors in 42 dogs. J. Vet. Intern. Med. 15: 183-189. [Medline] [CrossRef]

13. Rassnick, K. M., Goldkamp, C. E., Erb, H. N., Scrivani, P. V., Njaa, B. L., Gieger, T. L., Turek, M. M., McNiel, E. A., Proulx, D. R., Chun, R., Mauldin, G. E., Phillips, B. S. and Kristal, O. 2006. Evaluation of factors associated with survival in dogs with untreated nasal carcinomas: 139 cases (1993-2003). J. Am. Vet. Med. Assoc. 229: 401-406. [Medline] [CrossRef]

14. Théon, A. P., Madewell, B. R., Harb, M. F. and Dungworth, D. L. 1993. Megavoltage irradiation of neoplasms of the nasal and paranasal cavities in 77 dogs. J. Am. Vet. Med. Assoc. 202: 1469-1475. [Medline]

15. Withrow, S. J. 2013. Tumors of the respiratory system. pp. 432-462. In: Small Anim Clin Oncol, 5th ed. (Withrow, S. J., Vail, D. M. and Page, R. L. eds), Elsevier, St. Louis. 